\title{
Entours d'Édouard Glissant, textes réunis par Valérie Loichot
}

\section{Elena Pessini}

\section{Q OpenEdition}

10 Journals

\section{Édition électronique}

URL : http://journals.openedition.org/studifrancesi/2315

DOI : 10.4000/studifrancesi.2315

ISSN : 2421-5856

Éditeur

Rosenberg \& Sellier

\section{Édition imprimée}

Date de publication : 1 avril 2014

Pagination : 196-197

ISSN : 0039-2944

\section{Référence électronique}

Elena Pessini, « Entours d'Édouard Glissant, textes réunis par Valérie Loichot », Studi Francesi [En ligne], 172 (LVIII | I) | 2014, mis en ligne le 01 avril 2014, consulté le 18 septembre 2020. URL : http:// journals.openedition.org/studifrancesi/2315; DOI : https://doi.org/10.4000/studifrancesi.2315

Ce document a été généré automatiquement le 18 septembre 2020.

\section{(c) (i) (9)}

Studi Francesi è distribuita con Licenza Creative Commons Attribuzione - Non commerciale - Non opere derivate 4.0 Internazionale. 


\title{
Entours d'Édouard Glissant, textes réunis par Valérie Loichot
}

\author{
Elena Pessini
}

\section{RÉFÉRENCE}

Entours d'Édouard Glissant, textes réunis par Valérie LоICHOT, «Revue des Sciences Humaines», n. 309, janvier-mars 2013, pp. 258.

1 L'introduction de ce numéro de la «Revue des Sciences Humaines» est placée sous le sceau de l'émotion et de l'amitié, c'est en effet une ancienne élève d'Édouard Glissant lorsqu'il était professeur à l'université de Baton-Rouge, en Louisiane, qui réunit un ensemble d'études consacrées à l'écrivain martiniquais disparu en 2011 (Valérie Loichot souligne que ces études paraissent à la mémoire de Glissant). Le texte d'ouverture s'intitule, non sans un certain humour, «Au double-maître» et reprend une plaisanterie avec laquelle l'écrivain lui-même avait l'habitude de commencer ses cours, en jouant sur l'homophonie entre sa fonction d'enseignant (maître) et l'expression utilisée dans le langage familier pour indiquer un individu de grande taille (double mètre). On reconnaîtra là, évidemment, une pratique du conteur antillais qui, pour capter l'attention de son auditoire, se devait de l'amuser et de l'étonner. Toutefois, malgré cet incipit, les travaux sont on ne peut plus sérieux et gravitent autour de trois grands axes qui constituent les différentes parties du recueil: Relations, Entours, Politiques. Si la production littéraire est parfois convoquée - Le Quatrième siècle est en particulier le roman sur lequel reviennent plusieurs études -, les critiques concentrent leurs réflexions sur Glissant théoricien de la Relation, philosophe et penseur à l'écoute des soubresauts du monde contemporain. La première section qui regroupe quatre essais s'occupe des rapports qui peuvent être établis entre les théories (philosophiques et esthétiques) élaborées par Édouard Glissant et d'autres pensées ou d'autres auteurs. L'étude la plus surprenante est sans aucun doute la première, intitulée Le Moyen Âge d'Édouard Glissant: codicologie, philologie et Relation, où le médiéviste Jean-Pascal POUZET considère les méthodes codicologiques à l'aune de la théorie de la Relation. L'opération 
pourrait sembler risquée, et elle l'est, mais les perspectives offertes par cette approche permettent de creuser le rapport entre Glissant et le Moyen Âge, cette époque historique n'ayant cessé de fasciner l'écrivain. Dominique CHANCÉ, dans Édouard Glissant, de l'anthropologie à l'esthétique, souligne l'évolution du théoricien martiniquais n'oublions pas sa formation d'ethnographe - qui s'éloigne progressivement de l'anthropologie classique dont il est encore assez proche au moment de la rédaction $\mathrm{du}$ Discours antillais et du roman La Case du Commandeur qui paraissent tous deux en 1981. Cette étude montre également comment et dans quelle mesure le concept de créolisation glissantienne est employé par certains anthropologues dans leur approche au fonctionnement des sociétés contemporaines multiculturelles. Lorsque la rastalogie, la dub poetry et l'Antillanité-Tout-Monde d'Édouard Glissant entrent en relation, d'Anny Dominique cuRTIus éclaire les points de contact entre les théories glissantiennes et des formes culturelles qui s'enracinent dans la Caraïbe anglophone. Kathleen GYSSELS, en conclusion de cette première partie, examine le parcours d'André Schwarz-Bart et les liens qui le rapprochent d'Édouard Glissant. Dans Un long compagnonnage: Glissant et Schwarz-Bart face à la diaspora, elle s'interroge sur le rapport que l'un et l'autre ont respectivement entretenu avec deux formes de diaspora, la diaspora juive et la diaspora africaine. La deuxième partie a pour titre un mot cher à Édouard Glissant, «entours», qui, comme le précise Valérie LоICHоT, «dépasse en portée [le mot] 'paysage'. L'entour désigne un lieu-paysage porteur de mémoire et de langue dans lequel le naturel, le culturel, l'écologique et le politique sont indiscernables» (p. 11). Le texte de Jean-Pol MADOu (D'échos en cohées: De la Martinique à l'île de Pâques) se focalise sur une des dernières œuvres de Glissant, La Terre magnétique, que Sylvie Séma a illustrée de ses dessins, à la fois méditation philosophique, enquête anthropologique et récit de voyage. Un récit de voyage que l'auteur effectue par personne interposée puisque en réalité il ne s'est jamais rendu personnellement sur l'île et qu'il ne l'a connue que grâce à la caméra de son épouse, Sylvie Sémavoine. L'écrivain n'en est pas moins fasciné par les statues de pierre de l'île de Rapa-Nui qui le conduisent à creuser, à redéfinir son concept du Tout-Monde et à établir une relation féconde entre la Caraïbe et l'Océanie. La contribution de Benoît CONORT, "Le Quatrième siècle" du paysage: relation/vertige de l'opacité, étonne non pas tant par son contenu - il s'agit d'une étude qui se penche sur la présence et sur l'importance des éléments naturels dans le roman - mais par sa forme poétique, par son style très glissantien auquel la critique littéraire ne nous a pas habitués. Naïma HACHAD dans Paroles de l'abîme d'Édouard Glissant et Abdelkébir Khatibi, rapproche Glissant du poète, critique et romancier marocain à travers le motif littéraire de la mer. Au-delà du motif poétique que d'autres poètes comme Mallarmé, Baudelaire ou Lautréamont ont exploité pour signifier le passage à une écriture antiromantique, les deux écrivains considèrent que ce lieu est un lieu «de perte et de perdition, mais aussi un lieu de mémoire et de renaissance. Cette ambiguïté donne lieu à des récits fragmentés, en dérive, troués de silences implacables, mais aussi hantés par des cris et des murmures qui, sans cesse, cherchent à se constituer en voix pleine et signifiante» (p. 126). L'article de Claude CAVALLERo, Les enjeux du discours épique dans "Le Quatrième siècle" d'Édouard Glissant, clôt cette deuxième partie en soulignant l'importance du second roman que Glissant publia en 1964 et qui constitue, en quelque sorte, le cœur de tout l'univers romanesque auquel il donnera naissance. Soucieux de relire l'Histoire en partant du point de vue de ceux qui la subirent, l'écrivain martiniquais n'en met pas moins en œuvre une «écriture épique très personnelle et à propos de laquelle il n'exclut pas le doute» (pp. 150-151). La troisième section 
s'interroge sur la fonction politique des textes d'Édouard Glissant. Nick NESBITT dans Politiques et poétiques: les errances de l'absolu, établit un état des lieux du débat théorique actuellement en cours dans les textes de Peter Hallward, Celia Britton et Chris Bongie sur les prises de position politiques de Glissant et sur l'évolution de la présence d'une préoccupation d'ordre politique, notamment dans ses essais théoriques. C'est le thème de l'opacité que Celia BRITTON affronte dans Cacher à l'autre, cacher à soi-même: l'obscurité du langage dans l'œeuvre d'Édouard Glissant. Nous suivons chronologiquement l'évolution de cette idée maîtresse à travers Le Discours antillais, Poétique de la Relation, Faulkner, Mississippi et Mémoires des esclavages. Cette analyse des stratégies de ruse, de détournement, de dépistage que Glissant met en œuvre dans sa poétique nous éclaire sur la démarche de l'écrivain lorsqu'il fait de ces pratiques un moyen d'action et de réflexion politiques. Dans son article L'identité-résistance: Antillanité, Relation, Opacité, $\mathrm{H}$. Adlai MURDOCH fait dialoguer trois concept-clés de la pensée glissantienne et, en observant les liens qui tissent leurs rapports, montre comment Glissant élabore un nouveau concept d'identité qui n'est pas seulement opératoire en milieu caraïbe mais qui s'applique à l'échelle mondiale lorsqu'il est nécessaire de reconsidérer les idées de nations et de frontières. Cette troisième section se conclut par l'analyse du texte Mémoires de l'esclavage: la fondation d'un centre national pour la mémoire des esclavages et de leurs abolitions à travers lequel Édouard Glissant prend directement la parole sur la scène politique au lendemain de la loi du 21 mai 2005, dite loi Taubira, par laquelle la France reconnaît "que la traite négrière transatlantique et l'esclavage perpétrés à partir $\mathrm{du} \mathrm{xv}^{\mathrm{e}}$ siècle contre les populations africaines déportées en Europe, aux Amériques et dans l'Océan Indien constituent un crime contre l'humanité» (p. 203). Dans Mémoires des esclaves: le dernier chantier d'Édouard Glissant, Cilas KEMEDJO considère que le projet de l'auteur est un chantier mémoriel où pourraient confluer la mémoire antillaise et la mémoire européenne pour esquisser une mémoire globale, une mémoire partagée. Ce numéro de la revue présente en conclusion un autre groupe de textes rassemblés sous un titre plus affectif: Offrandes. Les amis et collègues d'Édouard Glissant y participent, selon qu'ils sont écrivains ou critiques, par un texte très personnel allant du très beau poème écrit par Ernest PÉPIN au moment du décès de l'écrivain (Pour Édouard Glissant), à la contribution d'Alexandre LeupIN qui reparcourt le fil des conversations échangées avec l'auteur lorsque ce dernier enseignait avec lui à l'université de Baton Rouge (L'appel du futur: les essais d'Édouard Glissant). Bernadette ADAMS CAILLER et Hanétha VÉTÉ-CONGO-LEIBNIZ apportent également leur offrande en signant respectivement Rêves sur les funérailles religieuses d'Édouard Glissant et L'Acomat. Le Féal. Édouard Glissant. L'ensemble des études confirme, si besoin en était, la richesse de la pensée glissantienne, son extrême actualité et le dialogue fructueux qu'elle permet d'établir avec d'autres systèmes de pensée. 